\title{
EDITORIAL
}

\section{Technical Reviews start in Polymer Journal}

Polymer Journal (2016) 48, 559; doi:10.1038/pj.2016.36

$\mathrm{P}_{\mathrm{R}}^{o}$ olymer Journal published two types of reviews: Review and Focus Review. Focus Review is relatively a new category in Polymer Journal. It has started from the June issue, $2012,{ }^{1}$ which is the special issue of self-assembled materials. ${ }^{2}$ Since then we have published 55 Focus Reviews. From the current issue, we start Technical Review. Technical Reviews will be mostly written by authors from the industry. Polymers are key materials in the industry. Technical Reviews report some technological aspects on polymers in industrial materials. It is published on invitation. The first Technical Review was written by researchers of Electronic Materials Research Department, Denka (previous name: Denki Kagaku Kogyo) Co. Ltd. ${ }^{3}$ The title of the Technical Review is 'Development of next-generation temporary fixing agent for electronic materials.' The review reports on polymer films that can be easily peeled off after hot water immersion. This property is important for processing electronic materials such as semiconductors and mobile phones. The authors received the Award of the Society of Polymer Science, Japan (Technology), 2012. I hope the Technical Review will give us useful information on the latest technological aspects in industries and suggestions for future development of polymeric materials.

Takashi Kato

Editor-in-Chief

1 Kato, T., Aoshima, S. \& Kikuchi, H. Special issue: self-assembled materials. Polym. J. 44, 451 (2012).

2 Kuzuya, A. \& Ohya, Y. DNA nanostructures as scaffolds for metal nanoparticles. Polym. J. 44, 452-460 (2012).

3 Kurimura, H., Watanabe, J., Oshima, K., Yoda, K. \& Shimizu, N. Development of a next-generation temporary fixing agent for electronic materials. Polym. J. 48 565-570 (2016). 